ISSN 2179-345X

Licenciado sob uma Licença Creative Commons

\title{
Desenvolvimento e direito de autor na sociedade de informação
}

\section{Development and copyrights in the information society}

\author{
José Augusto Fontoura Costa ${ }^{[a]}$, Fernanda Sola ${ }^{[b]}$ \\ [a] Professor da Universidade Católica de Santos e da Universidade do Estado do Amazonas, livre- \\ docente em Direito Internacional pela FADUSP, Santos, SP - Brasil, e-mail: jaugfcostag@hotmail.com \\ ${ }^{[b]}$ Mestre em Direito Ambiental pela Universidade Católica de Santos (UniSantos), Santos, SP - Brasil.
}

\section{Resumo}

Este trabalho é um ensaio sobre a interação entre os conceitos de desenvolvimento, direitos de propriedade intelectual, principalmente os direitos de autor, e as transformações resultantes da sociedade de informação. Considerando que os serviços e os bens imateriais são as mais importantes fontes de riqueza, a estrutura jurídica dos direitos de propriedade intelectual e os gastos governamentais para sua garantia são dados que influem sobre a riqueza e o desenvolvimento. Portanto, é necessário compreender como os institutos e órgãos jurídicos conformam a circulação econômica de bens e serviços. Para tratar essa questão, este ensaio propõe uma análise multidisciplinar apoiada em conceitos jurídicos e econômicos, em especial com respeito à abordagem da análise econômica do direito para a avaliação dos regimes e institutos jurídicos.

Palavras-chave: Direitos de autor. Desenvolvimento. Propriedade intelectual. Sociedade da informação. 


\section{Abstract}

Essay on the interaction among the concepts of development, intellectual property rights, mainly the copyrights, and the changes brought by the information society. Considering the services and immaterial goods as the most important sources of wealth, the legal structure of intellectual property rights and the governmental expenditures to grant them are data which affects the welfare and development. Therefore, it is necessary to understand how the legal institutions and organizations shape the economic circulation of goods and services. In order to treat this question properly, the essay proposes a multidisciplinary analysis backed by legal and economic concepts, especially regarding the law and economics approach to the economic assessment of legal regimes and institutions.

Keywords: Copyright. Development. Intellectual property. Information society.

\section{Desenvolvimento}

Ao que parece, a clareza do sentido de uma palavra ou expressão é inversamente proporcional à força que esta tem em sua dimensão emotiva. Quanto mais seja percebida como intensamente adorável ou odiosa, uma palavra ou expressão tende a ter significados menos precisos. É por isso que, como no que diz respeito à 'justiça' ou 'democracia', o 'desenvolvimento' se apresenta, hoje, como pouco definido e polissêmico.

A polissemia é a característica de palavras ou expressões que têm dois ou mais significados diferentes, embora relacionados. Assim, 'cravo' pode se referir a um tipo de prego, bem como a um tempero, uma flor ou um instrumento musical. Embora seja possível encontrar correlações entre os vários sentidos, não é razoável confundir o ingrediente culinário com o insumo do carpinteiro, sob pena de uma severa indigestão. Não se trata, evidentemente, de vagueza, mas de núcleos diversos de significação.

No que se refere à vagueza ou imprecisão, por outro lado, termos que lidam com intensidades não quantificadas, como 'claro', 'grande' e 'vermelho' tendem a deixar ao seu redor uma zona cinzenta, não ficando 
muito bem delimitado onde começa ou termina a abrangência da noção. De maneira menos evidente do que nos termos exemplificados, os sentidos de algumas palavras pressupõem intensidades, como a justiça: para saber seu, uma pena ou uma indenização podem ser consideradas justas, mas é preciso avaliar a sua intensidade.

'Desenvolvimento', como veremos, é uma palavra tanto polissêmica quanto vaga. Em primeiro lugar, é preciso deixar claro que o termo se refere a um processo, não a um estado. Nesse sentido, pode-se dizer que se trata de um fenômeno dinâmico tendente ao estado de desenvolvido. O que já se encontra nessa condição, portanto, não pode se desenvolver. O parâmetro de desenvolvimento é, portanto, dado pela observação dos países desenvolvidos.

Um processo comumente associado ao desenvolvimento é o crescimento econômico. Seu indicador mais difundido é o produto nacional bruto (PNB), que pode ser definido como "o valor de todos os bens finais e serviços produzidos por fatores próprios de produção no decorrer de um dado período", embora no Brasil o indicador mais amplamente adotado seja o produto interno bruto (PIB), que é o "valor dos bens finais produzidos no país" (DORNBUSCH; FISCHER, 1991, p. 38-39). ${ }^{1}$

Embora seja inegável a relação entre crescimento e desenvolvimento, não há dúvida de que se trata de noções diversas. A variação da renda per capita, que corresponde ao PIB dividido pela população, é um indicador melhor do que a simples taxa de crescimento, mas, apesar disso, deixa de considerar aspectos significativos, como, por exemplo, a distribuição de renda.

O primeiro núcleo de significado de desenvolvimento, portanto, se refere a critérios quantitativos, os quais podem se referir a crescimento, renda per capita ou outros indicadores referentes à industrialização,

1 A diferença entre os dois é que o PNB considera os bens produzidos no exterior com a aplicação de fatores nacionais. Os honorários recebidos por um advogado brasileiro que presta consultoria na Argentina fariam parte do PNB brasileiro e do PIB argentino, mas não do PIB brasileiro ou do PNB argentino. 
alfabetização e expectativa de vida. Essa percepção conduz a uma percepção gradualista do desenvolvimento, conforme a qual o incremento dos índices relevantes assinala um processo contínuo de melhora.

É com relação a essa percepção, entretanto, que outro núcleo de significado começa a ser construído, a partir dos anos 1950, tendo como marco a Conferência de Bandung, em 1955. Na América Latina, as teorias da dependência apontaram, especialmente a partir do trabalho da Comissão das Nações Unidas para a América Latina (Cepal), e em particular de Raul Prebisch, que elaborou a hipótese da deterioração dos termos de intercâmbio, conforme a qual os países exportadores de commodities tendem a obter cada vez menos divisas com o mesmo nível de exportações (BIELSCHOWSKY, 1996).

Dessa perspectiva, a substituição de importações mediante processos de industrialização, com a imposição de barreiras seletivas à importação, foi adotada como política por diversos países, inclusive o Brasil. Não obstante, mesmo essas políticas foram insuficientes para superar o desequilíbrio departamental, decorrente do ciclo do produto e da manutenção, nos países centrais, do investimento em pesquisa e tecnologia (LACERDA et al., 2005).

Pode-se, portanto, falar de duas noções conflitantes de desenvolvimento. Uma delas, gradualista, identifica o subdesenvolvimento com um atraso histórico, o qual pode ser solucionado mediante a aceleração do crescimento resultante de ajuda internacional e regimes comerciais e financeiros estáveis. Por outro lado, o subdesenvolvimento estrutural resulta da deterioração dos termos de intercâmbio e do desequilíbrio departamental dos processos de industrialização tardia.

$\mathrm{Na}$ atualidade, porém, o sentido do desenvolvimento ultrapassou o âmbito estritamente econômico para levar em conta aspectos que denotam melhor qualidade de vida. É nesse sentido que foram desenvolvidos por Amartya Sem e Gustav Ranis, a pedido do PNUD, os índices de desenvolvimento humano (IDH), que consideram quatro variáveis: o PIB per capita, a expectativa de vida, a escolaridade obrigatória e os índices de alfabetização de adultos (SAMUELSON; NORDHAUS, 1999, p. 540). 
A noção de desenvolvimento como liberdade, ademais, agrega a dimensão institucional e política à análise dos padrões de conforto e dignidade, trazendo novas e importantes variáveis à tona, como a liberdade política, as oportunidades sociais, a transparência e a segurança, além de assumir que a liberdade é tanto instrumental quanto constitutiva do desenvolvimento (BARRAL, 2005; SEN, 1999).

Um sentido particularmente importante para desenvolvimento é o de sustentabilidade, que limita o crescimento às demandas das futuras gerações, considerando as dimensões ecológica, econômica e social (JUSTE, 1999, p. 33). O caráter transgeneracional já aparecia na Declaração de Estocolmo, de 1972, mas tomou sua forma mais conhecida com a formulação do Relatório Brundtland, ${ }^{2}$ de 1987 , como ficou conhecido o documento elaborado pela Comissão Mundial sobre o Meio Ambiente e Desenvolvimento, intitulado Nosso futuro comum, como a forma de desenvolvimento que "satisfaz as necessidades do presente sem comprometer a possibilidade de que as gerações futuras satisfaçam suas próprias necessidades" (NANDA, 2005).

Retomando, então, a noção de polissemia, pode-se afirmar que a noção de desenvolvimento tem mais de um núcleo de significado por duas razões. Em primeiro lugar, as percepções gradualista e estruturalista se constroem em torno de noções bastante diversas de desenvolvimento: uma é principalmente quantitativa e fortemente ancorada no crescimento, seja econômico, seja de outros indicadores, como os que compõem o IDH; a outra é qualitativa e não se confunde com o mero incremento de índices, mas na sua relação estrutural com os processos produtivos e sociais. Em segundo lugar, ao se tratar das modalidades qualificadas de desenvolvimento, é possível, desde logo, identificar núcleos de referência nas noções de desenvolvimento humano e de desenvolvimento sustentável, sem prejuízo de outros possíveis tipos, como o industrial, social e setorial, entre outros.

2 Relatório Brundtland, cap. 2, art. 1. Disponível em: <http:iiwww.worldinbalance.net/pdf/1987brundtland.pdf>. Acesso em: 21 out. 2008. 
Além disso, principalmente no que se refere ao desenvolvimento compreendido de maneira gradualista, a classificação em graus de desenvolvimento é possível a partir do estabelecimento de critérios discricionários: os desenvolvidos apresentam determinados índices acima de um dado patamar; os emergentes, entre duas cifras; e os de menor desenvolvimento relativo, abaixo de dados limites. O uso natural do termo, portanto, apresenta-se como vago - pelo menos potencialmente (CARRIÓ, 1990) -, sendo possível sua definição mediante a fixação artificial de parâmetros.

\section{Direitos de autor}

Não se busca, no âmbito deste artigo, definir e contextualizar os direitos de autor. Concentra-se a atenção, assim, na compreensão da possível influência desses direitos sobre os processos de desenvolvimento.

Antes de qualquer coisa, é importante rememorar que o Direito cumpre algumas funções de grande importância para a estruturação das modernas economias. Ele estabelece, em primeiro lugar, um marco institucional mínimo que possibilita o funcionamento das economias de mercado, na medida em que estabelece institutos, como a propriedade privada e os contratos, baseando-os na ampla liberdade individual garantida pelas constituições liberais e os códigos de Direito Privado. Mais do que isso, servem para a correção das chamadas falhas de mercado: custos de mobilização dos fatores produtivos; falta e assimetria de informação, concentração dos agentes econômicos, externalidades e ausência de oferta de bens coletivos. Por fim, o Direito é, ainda, instrumento de implementação de políticas públicas, as quais podem buscar metas públicas diversas da simples manutenção do bom funcionamento do mercado (NUSDEO, 2006). O estabelecimento e a regulação dos direitos de autor podem, com efeito, ser compreendidos em qualquer dessas três dimensões da ação estatal mediante o Direito.

Os direitos de autor são uma das espécies de institutos abrangidos pela categoria da propriedade intelectual. Sua função primordial é 
a de estabelecer critérios de excludibilidade, os quais tornam tais direitos objetos passíveis de trânsito no mercado. Em outras palavras, como as demais posições jurídicas derivadas do instituto da propriedade, os direitos de autor subjetivos se tornam comercializáveis apenas na medida em que é possível excluir as pessoas de sua utilização e fruição. Como esclarecem Sol Picciotto e David Campbell (2009), não há nenhuma diferença essencial entre a propriedade de tangíveis ou intangíveis, já que ambos dependem da possibilidade de excluir terceiros, o que pode se dar mediante instrumentos estatais (como os direitos juridicamente estabelecidos, sistemas jurisdicionais e sistemas de cumprimento forçado) ou com o estabelecimento de instituições não estatais (como a condenação moral da pirataria, o estabelecimento de protocolos tecnológicos excludentes de não membros e a construção publicitária do prestígio associado a marcas) e, até mesmo, por meio da própria autotutela (como na resistência contra a turbação e o esbulho e na capacidade física e tecnológica de afastar potenciais usuários).

O primeiro sentido do direito de autor, portanto, é o de reforçar a criação de objetos jurídicos passíveis de apropriação mediante a titularidade dos direitos de uso, gozo e fruição. Cria-se, portanto, propriedade, a qual pode ser objeto de transações jurídicas. Nesse sentido, pode-se falar, portanto, na articulação de institutos que possibilitam as trocas em uma economia de mercado.

A principal justificativa utilitarista ${ }^{3}$ para o emprego de recursos estatais na criação e tutela de ativos privadamente apropriados é de que a sistemática do mercado implica a alocação mais eficiente de fatores produtivos, bem como a oferta da mescla de bens melhor adequada à satisfação de necessidades individuais. Especialmente significativa é, nesse sentido, a questão referente à oferta dos bens coletivos ${ }^{4}$ e, particularmente,

3 Há importantes topoi que justificam a prestação estatal de tutela ao direito de autor pela justiça em relação aos inventores e criadores. Não se discutirá tal linha argumentativa neste trabalho.

4 É comum, na Economia, a referência a bens públicos. Preferimos, aqui, a expressão bens coletivos, para evitar a possível confusão com o conceito jurídico de bens públicos. 
à ausência de oferta que se dá em razão da falta de preferências reveladas pelos consumidores.

Os bens coletivos são aqueles que podem satisfazer a necessidade de mais de um consumidor. É possível que a satisfação de todos os que podem se beneficiar do bem supere os custos de sua produção, mas que esta, mesmo assim, não se verifique em razão do custo demasiadamente elevado para um único consumidor. Imagine-se, por exemplo, que cinco pessoas desejem ouvir uma determinada canção em uma jukebox, mas o preço da execução, de $\mathrm{R} \$ 2,00$, é considerado muito alto pelos interessados, que estariam dispostos, por hipótese, a pagar $\mathrm{R} \$ 0,45$. Se todos se reunissem e aportassem $R \$ 0,40$, todos estariam mais satisfeitos ( $R$ \$ $0,40<\mathrm{R} \$ 0,45)$, mas isso não ocorre em condições de mercado, em decorrência da existência de custos de transação. ${ }^{5}$

Assim, em uma situação em que todos pudessem ter acesso livre aos bens resultantes da criação artística ou da produção técnico-científica, não haveria incentivo suficiente para os seus fornecedores, pois nenhum consumidor estaria disposto a pagar por algo que estivesse disponível para todos, independentemente de despesas.

Por outro lado, existem argumentos no sentido de que a produção artística e as inovações técnicas e científicas existem sem a necessidade da criação de direitos exclusivos e que a livre disponibilidade de informação, para o uso das descobertas, favorece a criatividade e a possibilidade de novos inventos.

Existem, decerto, formas alternativas de remuneração dos artistas e cientistas, como os subsídios estatais e o pagamento por prestação específica de serviços, como apresentações artísticas, palestras e consultorias. Por outro lado, no que tange às ações empresariais de pesquisa e

5 Pressupõe-se que, no mercado, os consumidores manifestam suas preferências mediante o pagamento do preço pelos bens que desejam adquirir. Se dois ou mais indivíduos se reúnem e tomam decisões econômicas conjuntamente, mediante a formação de uma pessoa jurídica, por exemplo, haverá um único agente, não múltiplos. A existência de custos de transação explica por que, na prática, muitas vezes essas reuniões não se realizam. Para um estudo detalhado, ver: COASE, 1937, 1970; WILLIAMSON, 1985. 
desenvolvimento, o segredo industrial e as vantagens de manter a vanguarda na oferta de produtos e serviços é incentivo suficiente para garantir pelo menos algum grau investimento.

Além disso, o acesso ao conhecimento e às inovações já existentes é que torna possível o progresso técnico e científico. A propriedade sobre substâncias, processos e modelos aumenta os custos de outros inventores e pesquisadores, levando a situações de monopólio, as quais são contrárias à eficiência de mercado. Isso, na atualidade, vale também para a cultura e as artes, pois à medida que a proteção de direito de autor estende seu âmbito de cobertura material e temporal, torna-se mais difícil encontrar referências recentes que não estejam protegidas.

Desse modo, deve-se deixar claro que existem alternativas para a conformação dos direitos de propriedade intelectual e, em particular, os de autor. Por um lado, é possível a equiparação desses direitos aos de propriedade, tendência que parece vir ganhando força com a ampliação do âmbito de abrangência dos direitos de autor para, por exemplo, alcançar os programas de computador, bem como a extensão dos prazos desses direitos. É importante deixar claro, no entanto, que essa opção gera custos para as autoridades estatais, uma vez que os mecanismos institucionais e jurisdicionais para a garantia dos direitos de propriedade intelectual são mantidos pelo Estado.

Pelo outro lado, as opções de facilitar o acesso aos direitos de autor, que também dependem de investimentos estatais, parecem vir sendo preteridas em relação às formas proprietárias. Isso, porém, não significa que essa alternativa tenha deixado de existir, mas apenas que as opções políticas e jurídicas vêm apontando, nos âmbitos internos e internacional, uma tendência a tornar os direitos de propriedade intelectual mais abrangentes e resistentes.

Como, porém, não se trata da proteção de direitos naturalmente atribuídos, mas da conformação jurídica de opções políticas, cabe perguntar a quais fins seguem as escolhas governamentais e legislativas. Nesse sentido, deve-se proceder à crítica da capacidade do modelo que intensifica a exclusividade em favor dos detentores dos direitos de autor em vista dos objetivos de desenvolvimento. 


\section{Desenvolvimento e direitos de autor}

Ao tratar do acesso e dos direitos referentes aos recursos genéticos, Sabrina Safrin (2004), seguindo a noção proposta por Michael Heller (1998), aponta para a hiperfitularidade como uma situação capaz de impedir o aproveitamento econômico de recursos. Trata-se, resumidamente, da tragédia dos anticomuns, situação na qual a sobreposição de direitos sobre a utilização de um bem impede sua oferta em condições de mercado, sendo necessário o concerto entre os agentes, o que pode emperrar em razão de elevados custos de transação.

Uma situação particularmente interessante é a que diz respeito às cadeias de utilização de descobertas e, portanto, de autorizações para o uso de fragmentos de informação protegidos.

Um dos âmbitos em que tal situação se revela de maneira vigorosa é o da produção de software, no qual a preponderância tendente ao monopólio da Microsoft ${ }^{\circledR}$ se funda na impossibilidade de livre desenvolvimento de novos produtos por terceiros, sendo necessário o pagamento de royalties. De modo algo irônico, o principal sistema concorrente, o Linux ${ }^{\circledR}$, é baseado na liberdade de acesso aos códigos fonte, o que permite um ambiente de maior cooperação e competitividade.

Também no campo dos produtos artísticos e culturais, as barreiras à criatividade e ao mercado se apresentam na forma de direitos de autor. Nos tempos atuais, os referenciais culturais acidentais são, muitas vezes, protegidos por direitos de autor. É algo que pode ser percebido nas crianças que transitam melhor pelo universo dos personagens Disney ${ }^{\circledR}$ do que pelas tradições e lendas nacionais. Mesmo sem se fazer um juízo de valor sobre as vantagens e desvantagens de escolher o folclore ou a cultura pop, o fato é que a expressão cultural dessas pessoas será limitada, no futuro, pelos direitos de autor sobre as referências culturais e artísticas. Parte da crítica articulada pela pop art e pelos objetos-pastiche pós-modernos aponta para essa mesma direção. A criação artística e a produção cultural, portanto, ficam cada vez mais restritas em virtude da ampliação de direitos de propriedade. Mas como isto afeta o desenvolvimento? 
Considerando a concepção estrutural do desenvolvimento, conforme a qual as relações internacionais de dependência são constituídas em torno da centralização de certas atividades em alguns países, o incremento da proteção da propriedade intelectual e dos direitos autorais pode servir como um instrumento de manutenção das assimetrias em favor de países centrais e das empresas que sejam detentoras dos blocos de informação necessários para inovar. As ações de pesquisa e desenvolvimento terminam por se concentrar nas matrizes, garantindo sua prosperidade mediante a cobrança de royalties, ao mesmo tempo em que as defende da potencial concorrência. As críticas à elevação dos padrões internacionais de proteção, mediante o acordo TRIPs, e de outros instrumentos como os tratados de livre comércio, tomam essa direção. Da mesma forma, as exigências de transferência de tecnologia em acordos internacionais são voltadas a mitigar as barreiras à circulação e utilização de informação protegida.

Além disso, se o desenvolvimento também é entendido em termos de bem-estar e da qualidade de vida, deve-se ressaltar que estes também dependem do exercício dos direitos à liberdade de expressão, inclusive artística, e aos bens culturais. Como a restrição ao acesso e uso de bens culturais relevantes, limitam-se os direitos pessoais, cujo exercício passa a ser condicionado ao pagamento de preços aos detentores de direitos sobre a produção anterior. Uma vez que, atualmente, os fluxos econômicos e eletrônicos vêm se tornando fundamentais para quaisquer atividades, é ainda possível perceber que, na sociedade de informação, os limites decorrentes da propriedade intelectual podem retardar o desenvolvimento, pois dificultam a utilização das peças de informação e podem, em muitas circunstâncias, levar a situações de tragédias de anticomuns.

A vida e a produção se tornaram indissociáveis das novas formas de fluxo informacional, redesenhando a própria arquitetura das atividades do dia a dia. As próprias atividades produtivas capazes de agregar mais valor estão se afastando dos modelos industriais e fabris tradicionais e passam por uma reestruturação profunda. Esse tema, porém, não será abordado nesta apresentação. 
O que importa, aqui, é deixar claro que a adoção de um modelo de propriedade intelectual, conforme o qual os direitos de autor garantem a exclusividade individual das informações, é resultado de uma opção política a respeito de como o Estado deve empregar seus recursos para alocar direitos e obrigações. Além disso, essa escolha tem efeitos sobre o próprio desenvolvimento, os quais podem ser negativos, seja no que se refere à sua concepção estruturalista ou dependentista, seja a sua modalidade qualificada em termos de qualidade de vida e desenvolvimento humano. A crítica e a discussão dos modelos e formas de proteção e incentivo à produção artística, cultural, científica e tecnológica, portanto, não podem cessar, uma vez que seus efeitos para a atividade econômica, e, sobretudo, para a vida, são importantes demais para que elas sejam relegadas à condição de mera opção técnica.

\section{Sociedade de informação, desenvolvimento e direitos de autor}

Embora a noção de economia do conhecimento tenha surgido com Fritz Machlup (CRAWFORD, 1983), a expressão 'sociedade da informação’ foi utilizada por Peter Drucker (1970) com o objetivo de designar a sociedade rearranjada a partir da mudança do paradigma produtivo, denominando assim uma seção de seu Uma era da descontinuidade.

O que se denomina sociedade de informação também recebe, com algumas alterações, o nome de sociedade informacional, economia do conhecimento, sociedade pós-industrial, sociedade pós-moderna e sociedade em rede, entre outros nomes. Preferiu-se manter a expressão 'sociedade de informação' por ser esta a mais comumente utilizada.

Para os fins deste estudo, importa ressaltar que, na chamada economia de informação, há tanto uma redefinição dos bens econômicos centrais como dos processos produtivos. Os produtos de maior valor agregado deixaram de ser os bens móveis industrializados, como automóveis e eletrodomésticos, para ser bens incorpóreos, como programas de 
computador, filmes e gravações musicais. Os processos de produção, por seu turno, deixam de ser aqueles desenvolvidos nas linhas de montagem das fábricas, que concentram em um único local as máquinas necessárias, pois na medida em que os bens se desmaterializam o foco passa a ser no projeto e, portanto, em estruturas menos hierarquizadas e rígidas de processo produtivo, com a consequente deslocalização do ambiente, já que as estações de trabalho já não precisam ser dispostas em linha ou concentradas no mesmo endereço.

É importante observar que Max Weber (1964, p. 119) aponta que a evolução da produção industrial para o capitalismo passa por vários estágios, que passam pelo monopólio dos recursos monetários, a apropriação exclusiva do direito de venda, a disciplina dos trabalhadores, a organização de oficinas e a especialização racional do trabalho, para culminar com a mecanização, descrita do seguinte modo: como último passo em direção à transformação capitalista das empresas de produção - mecanização da produção e do transporte, cálculo de capital. Todos os meios materiais de produção se transformam em capital (fixo ou de exploração). Todas as forças de trabalho - mãos. Mediante a transformação das empresas em associações de possuidores de valores o diretor também é expropriado e se transforma formalmente em 'funcionário'; o proprietário se converte materialmente no depositário de quem outorga o crédito (bancos).

Vilém Flusser (2007, p. 36), partindo do argumento de que o modo de produzir se relaciona com o modo de ser humano, lembra que:

a segunda Revolução Industrial expulsou o homem de sua cultura, assim como a primeira o expulsou da natureza, e por isso podemos considerar as fábricas mecanizadas como uma espécie de manicômio. [...] Já que a máquina deve estar situada no meio, devido ao fato de durar mais e de ter maior valor que o homem, a arquitetura humana terá de se submeter à arquitetura das máquinas. [...] A natureza inteira é atraída, de forma concêntrica, por essa sucção das máquinas.

Ainda para Flusser (2007), os processos produtivos de uma sociedade de informação, graças à desmaterialização e deslocalização, propiciariam 
uma reconstrução da humanidade. Exatamente como o homem primitivo, que sem mediação alguma apreendia a natureza com as mãos e, graças a elas, podia fabricar em qualquer momento e lugar os futuros funcionários, equipados com aparelhos pequenos, minúsculos ou até mesmo invisíveis, estarão sempre prontos a fabricar algo, em qualquer momento e lugar.

A percepção otimista de que as fábricas do futuro serão como universidades, em que a criação e a aprendizagem se realizam no fluxo informacional, parece, sim, expor um aspecto importante da sociedade de informação: a valorização do conhecimento como bem de produção e de consumo como resultado da libertação da necessidade de ocupar a força de trabalho na produção material.

Esse cenário, no entanto, apresenta duas dificuldades centrais: por um lado, a necessidade evidente de manter a produção dos bens materiais como suporte da vida, mesmo que influindo menos no estabelecimento de referências culturais. Não se tratará, porém, dessa questão neste ensaio. Por outro lado, a simples transferência de alguns custos para os produtores e consumidores (manter os equipamentos atualizados e constantemente conectados com a rede, além de arcarem com a formação do capital humano necessário para operar esstes instrumentos) dificilmente pode ser interpretada como uma reversão da última etapa de capitalização da produção descrita por Weber. Na medida em que a informação se converte em bens informacionais e, por conseguinte, a disponibilização do conhecimento passa a ser mediada por valores de troca, o próprio ser humano - como processador de conhecimento - passa a ser passível de capitalização, abrindo para o fluxo econômico aqueles aspectos da existência que, apesar da venda da força de trabalho, continuavam reservados.

Assim como na construção da economia industrial, as instituições jurídicas estão profundamente relacionadas com a formação de uma economia e uma sociedade informacionais. Da mesma forma que a proteção da propriedade e da circulação, mediante contratos, é base necessária para o mercado e a fábrica, a estruturação jurídica dos direitos de propriedade intelectual e sua circulação econômica internacional, mediante a rede mundial de computadores, têm e terão estritas conexões com as 
estruturas sociais e experiências humanas incrustadas nos novos âmbitos de referência cultural.

A tecnologia e a decorrente queda dos custos de informação e transporte implicam a diminuição relativa de alguns custos de transação, particularmente os que se referem especificamente à informação, que passa a ser disponível por menores preços. Trata-se de instrumentos disponíveis para os mais diversos atores e sujeitos, inclusive as empresas, os Estados, as organizações da sociedade civil e os indivíduos. Se a própria predominância estatal está ameaçada pelo incremento da importância de atores globais e infraestatais, levando à necessidade de novas estratégias para a própria manutenção da capacidade governamental de induzir e controlar atividades econômicas (CASTELLS, 1999), as experiências e ações políticas também se deslocam do espaço da democracia representativa, tipicamente estatal, para os instrumentos diretos e participativos possibilitados por uma sociedade em rede.

Nesse ponto, as noções de desenvolvimento qualificadas por aspectos referentes à dignidade humana e qualidade de vida, inclusive na medida em que incorporam aspectos da liberdade e da participação na tomada política de decisões, devem ter em conta os ambientes e formas de interação virtuais. A criação e manutenção de espaços globalizados de intercâmbio e construção conjunta de objetos culturais e bens econômicos não só enfrenta o desafio do estabelecimento de critérios claros e condições para a efetividade dos direitos de propriedade intelectual, mas o de compreender se os novos movimentos da sociedade de informação estão conduzindo a uma realidade qualitativamente diversa da existente a partir da mecanização e da fábrica ou se, apesar de certa desordem passageira, o domínio da produção e da economia tende a se estender para espaços vitais ainda não ocupados pela lógica industrial.

\section{Referências}

BARRAL, W. Direito e desenvolvimento: um modelo de análise. In: BARRAL, W. (Org.). Direito e desenvolvimento. São Paulo: Singular, 2005. p. 31-60. 
BIELSCHOWSKY, R. Pensamento econômico brasileiro: o ciclo ideológico do desenvolvimento. 3. ed. Rio de Janeiro: Contraponto, 1996.

CARRIÓ, G. Notas sobre derecho y lenguaje. Buenos Aires: Abeledo Perrot, 1990. CASTELLS, M. Para o Estado-Rede: globalização econômica e instituições políticas na era da informação. In: PEREIRA, L. C. B.; WILHEIM, J.; SOLA, L. (Org.). Sociedade e Estado em transformação. São Paulo: UNESP; Imprensa Oficial, 1999. p. 147-171.

COASE, R. H. The nature of the firm. Economica, New Series, v. 4, n. 16, p. 386405, 1937.

COASE, R. H. The problem of social cost. Journal of Law and Economics, v. 3, p. 1-44, 1970.

CRAWFORD, S. The origin and development of a concept: the information society. Bulletin of the Medical Library Association, v. 71, n. 4, p. 380-385, 1983. Originalmente publicado em 1969 nos Estados Unidos.

DORNBUSCH, R.; FISCHER, S. Macroeconomia. 2. ed. São Paulo: Makron; MacGraw-Hill, 1999.

DRUCKER, P. F. Uma era de descontinuidade: orientação para uma sociedade em mudança. Rio de Janeiro: Jorge Zahar, 1970.

FLUSSER, V. A fábrica. In: CARDOSO, R. (Org.). O mundo codificado. São Paulo: Cosac Naify, 2007. p. 34-44.

HELLER, M. A. The tragedy of the anticommons: property in the transition from Marx to markets. Harvard Law Review, n. 111, p. 621-688, 1998.

JUSTE, J. Derecho internacional del medio ambiente. Madrid: McGraw-Hill, 1999.

LACERDA, A. C. de et al. Economia brasileira. 2. ed. São Paulo: Saraiva, 2005. NANDA, V. Sustainable development, international trade and the Doha agenda for development. Chapman Law Review, n. 8, p. 2, 2005. 
NUSDEO, F. Curso de economia. São Paulo: Revista dos Tribunais, 2006.

PICCIOTTO, S.; CAMPBELL, D. Afinal de contas, de quem é esta molécula? Perspectivas privada e social sobre a propriedade intelectual. Revista de Direito Empresarial, Curitiba, n. 11, p. 35-77, 2009.

SAFRIN, S. Hyperownership in a time of biotechnological promise: the international conflict to control the building blocks of lite. American Journal of International Law, n. 98, p. 641-685, 2004.

SAMUELSON, P. A.; NORDHAUS, W. D. Economia. 16. ed. Lisboa: MacGrawHill, 1999.

SEN, A. Development as freedom. Oxford: Oxford University Press, 1999.

WEBER, M. Economia y sociedad. 2. ed. Cidade do México: Fondo de Cultura Económica, 1964.

WILLIAMSON, O. E. The economic institutions of capitalism: firms, markets, relational contracting. Nova Iorque: Free Press, 1987.

Recebido: 21/11/2009

Received: 11/21/2009

Aprovado: 01/03/2010

Approved: 03/01/2010 